\title{
Wheat Production Information Retrieval System (WPIRS)
}

\author{
Suman Lata, \\ Computer Scientist, \\ Directorate of Wheat Research
}

\author{
Ajmer Singh \\ Agricultural Economist \\ Directorate of Wheat Research \\ Karnal
}

\begin{abstract}
A Database retrieval system for wheat data on area, production and yield (1960 to 2006) has been developed using ASP.NET technology. At the back end it uses 'SQL Server Management Studio Express (9.0)', an open source software for MYSQL database development. At the front end for ASP.NET programming it uses 'Visual Web Developer 2008 express 'edition. WPIRS has been developed using three layer architecture including Presentation layer, Application Layer and Data access Layer. Complete as well as selective data retrieval is possible with this software using 'Data List Reports' and 'Data Summary Reports' options respectively. A user friendly Graphic User Interface (GUI) has been created in WPIRS for submission of inputs. Multiple inputs such as State, districts and years with reference to Area/Production /Yield are submitted in a single go with this GUI and output is displayed on the same interface. The single screen GUI used for inputs and desired output gives a unified, familiar and user friendly look to the WPIRS package. The technology in terms of 'WPIRS' software package helps the decision makers to know the potentials and possibilities of wheat crop in different regions, states and districts of India. It fills the knowledge gap through information sharing and fast information access.
\end{abstract}

Keyword : Database, Asp.net, SQL server management studio, Visual Web Developer, Graphic user interface, Data access layer, Application Layer, Presentation Layer.

\section{INTRODUCTION}

Wheat is one of the first cereals known to have been domesticated due to its self pollinating ability. At the beginning of civilization, city-based societies emerged due to the domesticated wheat varieties only. It is one of the first crops that can be cultivated on a large scale and provides long term storage of seed. In the different regions of world there are substantial differences in wheat farming, trading policy, and wheat uses. Wheat is cultivated mainly in temperate and sub temperate regions of the world. Presently at global level, it occupies approximately 240 million hectare with production of approximately 600 million tones. China, India and U.S.A. are first, second and third, respectively in wheat production. In addition to these, other countries are Canada, Argentina, Australia, Soviet Russia, France and Italy where wheat is cultivated on larger scale.

Wheat is a temperate crop requiring low temperatures and most of the country is tropical. India raises almost exclusively winter wheat. The major wheat growing areas in India are located in the northern regions of the country. Major wheat growing states are Uttar Pradesh, Punjab, Haryana, Rajasthan, Madhya Pradesh, Gujarat and Bihar. The state of Uttar Pradesh produces the most wheat in India, accounting for 35 percent of India's total wheat production. The state of Punjab is the second largest producer of wheat in India, producing 22 percent of the nation's total wheat production. The planting of winter wheat begins about the first of October and runs through the end of December. Wheat will usually begin to head in January, with harvest following in March and May.

Large volume of data is generated about the wheat cultivation area, yield and production parameters all over India annually. Every year lot of research efforts are made by all scientists in conducting the field trials on wheat crop in different agro climatic zones on various aspects leading to better yield yielding varieties. The information regarding area under cultivation, state \& District wise production, fertilizer use is generated every year. This information is present in different forms and at different places. There is a need to assemble and document this huge information properly for making it user accessible in easiest way. Such a data bank created serves as store house for wheat crop research data. This repository helps scientist for any kind of detailed studies while deciding the parameters and future planning of wheat research.

Technology in terms of computer software is developed for menu based user friendly, fast information retrieval as per the need of time. Systematic storage of wheat crop data with details of cultivation area, yield, production parameters (state $\&$ district wise in India) in the form of database, fills up the information gap at institute and national /international level.

\section{OBJECTIVES}

The main objectives of the work under wheat production information retrieval system are:

1. To create the database on electronic media using data on wheat crop area, production and yield for all Indian states, district wise for the years from 1970 to 2006 .

2. To develop a user friendly software WPIRS (Wheat Production Information Retrieval System) for information retrieval in desired format in most convenient and simplest way.

3. To develop a complete databank WHAPY (wheat Area Production \& Yield) created for Institute's information repository, which is needed for future reference purposes.

4. To develop a system where the information retrieved from WHAPY (Database) with the help of WPIRS (Software Package) to facilitate the decision makers (researchers, planners) to know the potentials and possibilities for wheat crop in terms of area, production and yield in different regions of India.

\section{METHODOLOGY}

Structure of database for information storage is finalized to include detailed information of all the wheat data in terms of area, yield, production etc. This structure of data is used to create the database (WHAPY) using Database Management Software My SQL. Data is checked and digitized. At the back 
end it uses 'SQL Server Management Studio Express (9.0)', an open source software for MYSQL database development.

User friendly software (WPIRS) has been developed using ASP.NET technology for retrieval of information from this structured database. At the front end for ASP.NET programming it uses 'Visual Web Developer 2008 express edition'. WPIRS has been developed using three layer architecture including Presentation layer, Application Layer and Data access Layer. Complete as well as selective data retrieval is possible with this software using 'Data List Reports' and 'Data Summary Reports' options respectively. A user friendly Graphic User Interface (GUI) has been created in WPIRS for submission of inputs and display of outputs. The output format for report generation is decided, finalized and these reports are shared on electronic media.

NET is the new distributed computing platform developed by Microsoft and ASP.NET is its programming model for web development. Connecting to (and working with) a Microsoft Access database is not as simple as MS SQL Server. It is always possible to run into errors when working with Microsoft Access with ASP.NET, of course Connecting to a Microsoft Access database is easy, but when we try to retrieve some data within the database, our application may run into simple errors. To avoid these errors and compatibility problems, native databases are shifted into SQL instead of MS Access. MS SQL Server has its own security policies, and it is a concrete RDBMS when compared to MS Access.

\section{WPIRS ARCHITECTURE}

Three layers architecture is used for this software development. ASP.NET data source control model supports the three tier approach of software development through Object Data Source control. Three layers are

1. Presentation layer (ASP)

2. Application Layer (VB)

3. Data access Layer (SQL 2008 )

\subsection{Presentation Layer (GUI):}

This graphic user Interface is developed using Asp.net for getting user input in a friendly manner, providing dropdown lists and hints, while entering the data. The same single page layout for input as well as for output gives familiar and unified look to package, and makes it easy to use.

\subsection{Application Layer (APL) :}

It includes coding all predefined functions and stored procedures which are used for finding the records in database, depending upon different fields of information given by user as input. Those sorted (indexed) tables of information are referenced for processing information retrieval process.

For Web based software development Visual basic is used as scripting language. Server side application is implemented using Asp.net technology .This technology generates HTML pages according to user's action and request.

Package used: Visual Web Developer 2008 Express edition is used for software coding.

\subsection{Data Access Layer (DAL):}

This layer describes database connection and commands for updating, inserting and deleting records in the database. These commands are expressed through methods that are called with appropriate parameters. Object Data Source is associated with DAL through the command giving name of the DAL. DAL is implemented using SQL for creating database structure and tables of information.

Package used: SQL Server Management Studio Express 9.0 has been used for Database.

\section{FUNCTIONAL MODULES OF WPIRS PACKAGE}

This package has single user interface for simplicity and report generation is through data listing and data summary.

\subsection{Single GUI of WPIRS:- (Fig 1)}

Single Graphic User Interface (GUI): It contains drop down lists for selecting Indian states, districts of the state and years of data request for three types of databases namely wheat area under cultivation, wheat production and wheat yield. Single screen GUI gives unified, familiar and user friendly look to the WPIRS package.

\subsection{Data List Reports (Fig. 2)}

Two types of reports are generated from data in WHAPY database. Data list reports and Data summary reports from the data on area, production and yield for all the districts of selected state.

\subsection{Data Summary Reports:- (Fig 3)}

The summary report displays the requested data like on area/production /yield for all states for selected years. 


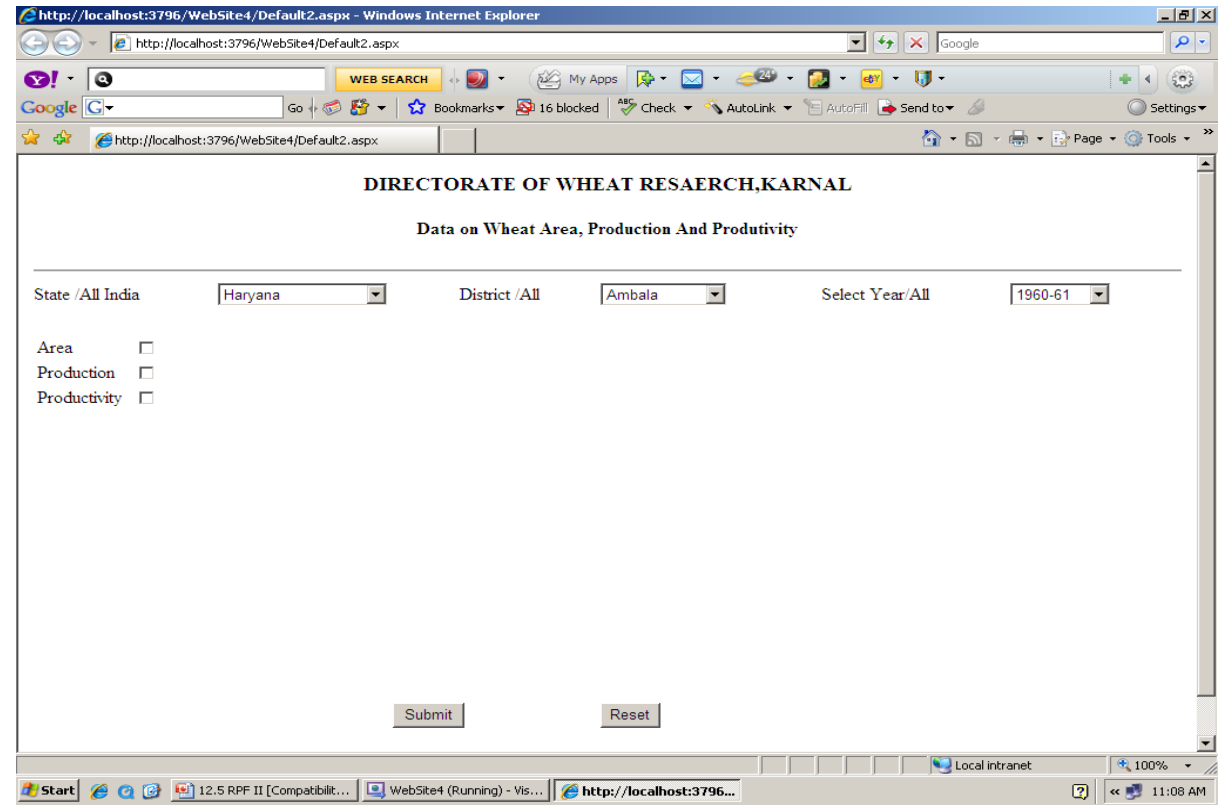

Fig. 1 Single Graphic User Interface (GUI) of WPIRS

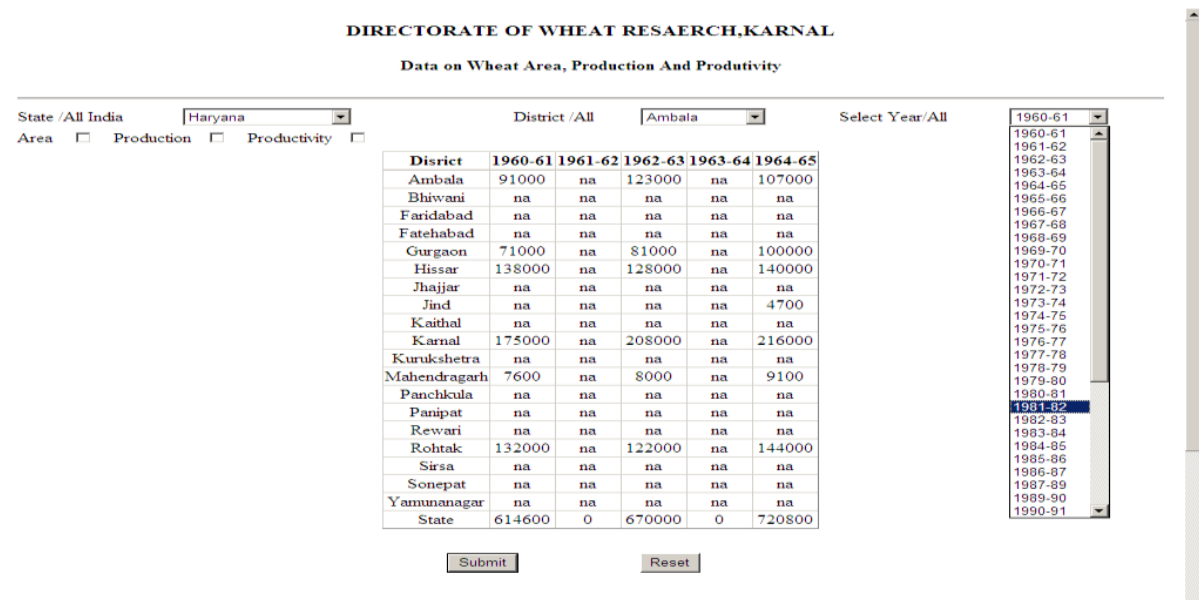

Fig. 2 Data List Reports of WPIRS

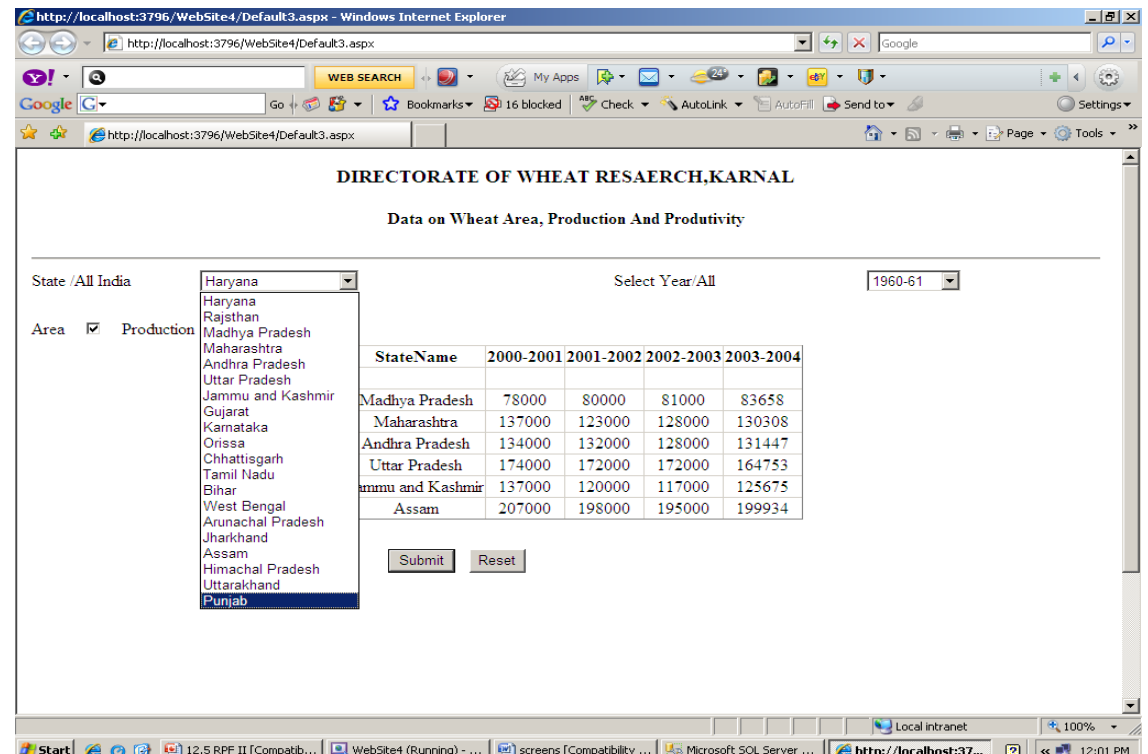

Fig. 3 Data Summary Reports of WPIRS 


\section{CONCLUSIONS}

Wheat Production Information System WPIRS is of much help to the personnel associated with wheat research. New and experienced workers can benefitted a lot by using WPIRS. This system acts like a ready reference and helps the workers to plan the work in wheat research area.

1. The need for proper storage of wheat crop data using proper Database structure on optical electronic storage media (CD, Pen Drive) using small surface is fulfilled.

2. The database developed on efficient and scientific lines provides repository of all past and current wheat production data at state and district level. This store house is accessed selectively by field experts and concerned scientists for further detailed research and studies or future planning.

3. Technology in terms of computer software (WPIRS) developed is used for information retrieval as and when required.

4. Using this databank WHAPY) the decision makers know the potentials and possibilities of wheat crop in different regions of India.

\section{ACKNOWLEDGEMENTS}

I duly acknowledge Dr. Ajmer Kundu for providing information and data on wheat .

\section{REFERENCES}

[1] Singh, SS., Sharma, RK., Singh, G., Tyagi B.S. and Saharan,M.S. 2011. 100 year of Wheat Research in India - A saga of distinguished achievement. Directorate of Wheat Research, Karnal, pp 281.
[2] Matthew, MacDonald., Beginning ASP.NET 3.5 in C\# 2008. Apress.

[3] Rankins, R., Jensen, P. , Bertucci ,P. 2003 . Microsoft SQL Server 2000: Unleashed : Sams Publishing “,ch. 28 ,PP $731-791$.

[4] Walther, S. 2007 . ASP.NET 3.5: Unleashed: Sams Publishing. ch. 3 ,pp337-657.

[5] Melton, J., Simon, R.A. 1993. Understanding the new SQL:A Complete Guide: Morgon Kaufmann Publisher.,ch 3 , pp43-60.

[6] Buser,D., Kauffman,J. Libre,J.T. and Francis, B.(1999). Beginning Active Server Pages Wrox Press Ltd.

[7] Desai, B.C. (1999). Introduction to Data Base System. Galgotia Publication, New Delhi.

[8] Deitel, Paul. Deitel,H.M. and Ayer, G.J. Simply Visual Basic 2008

[9] Troelsen, Andrew. Pro VB 2008 and the . NET 3.5 Platform.

[10] Dewson, Robin. ProSQL Server 2005.

[11] Spaaniaars, Imar . Get Started with Microsoft Visual Web Developer 2008 and ASP.NET 3.5.

[12] Spaaniaars, Imar. Beginning ASP.NET 3.5: in C\# and VB . 